\title{
KAROL WOJTYŁA, FILÓSOFO: ANTROPOLOGIA, CORPO E RELAÇÕES SOCIAIS
}

\author{
Jonas Matheus Sousa da Silva
}

Resumo: Evidencia a dignidade pessoal do corpo humano, integrado nos atos pessoais, através do pensamento antropológico de Karol Wojtyła. Expõe a dignidade pessoal na integração da reatividade somática na vontade humana, quando orientada pela norma personalista, que dá base à família e à comunidade humana, conforme os conceitos de participação e alienação nas relações "eu-tu" e nós".

Palavras-chave:Karol Wojtyła. Antropologia. Corpo humano.

\section{KAROL WOJTYLA, PHILOSOPHER: ANTHROPOLOGIE, CORPS ET RELATIONS SOCIALES}

Résumé: Il met en évidence la dignité personnelle du corps humain, intégrée dans les actes personnels, à travers la pensée anthropologique de Karol Wojtya. Il expose la dignité personnelle dans l'intégration de la réactivité somatique dans la volonté humaine, lorsqu'elle est guidée par la norme personnaliste, qui donne la base à la famille et à la communauté humaine, selon les concepts de participation et d'aliénation dans les relations «moi-toi» et «nous».

Mots-clés: Karol Wojtya. Anthropologie. Corps-humain.

\footnotetext{
${ }^{1}$ É graduado em Filosofia pelo Instituto de Estudos Superiores do Maranhão e mestrando em Filosofia pela Universidade Federal do Pará. Currículo Lattes: http://lattes.cnpq.br/8552714291150415.
} 
Karol Josef Wojtyła (1920-2005) é mais conhecido como “João Paulo II”, o carismático e diplomata papa polonês que guiou a Igreja Católica Romana de 1979 até 2005. Contudo, Wojtyła, como dramaturgo, poeta e filósofo, deu suas contribuições para o pensamento e à cultura, escrevendo vários textos filosóficos e literários antes de ser eleito Sumo Pontífice.

Em sua juventude, conforme redigiram Bernstein e Politi (1996), Wojtyła já havia lido, com o auxílio de seu pai, um tenente polonês, as obras: Kritik der reinen Vernunft (Crítica da Razão Pura), de Immanuel Kant; e Das Kapital (O Capital), de Karl Marx, ambas em alemão, a língua original. Porém, sua formação filosófica mais densa, sobretudo no campo da metafísica aristotélico-tomista, se deu no biênio filosófico, enquanto estava no seminário clandestino, preparando-se para ser padre. A construção de seu pensamento filosófico foi também influenciada, mais tarde, pelas esferas fenomenológica e personalista ${ }^{2}$.

Depois da ordenação sacerdotal, pós-graduou-se em Teologia e Filosofia, doutorandose com as teses: "A fé segundo São João da Cruz", em Teologia (1948); e a "Valoração sobre a possibilidade de construir a ética cristã sobre as bases do sistema de Max Scheler", em Filosofia (1954). Depois, Wojtyła, lecionou Filosofia moral nas Universidade de Cracóvia (Uniwersytet Jagielloński).e de Lublin (Uniwersytet Katolickii).

O filósofo espanhol Juan Manuel Burgos, em seu artigo intitulado "A Filosofia Personalista de Karol Wojtyła" (2006), agrupou o desenvolvimento da carreira filosófica de Wojtyła em quatro períodos, a saber: 1) a escola ética de Lublin; 2) o amor humano em "Amor e responsabilidade" (1960); 3) a antropologia em "Pessoa e ação" (1969); e 4) o caminho impedido nas áreas das filosofias interpessoal e social.

Para Juan Burgos (2006, p.3), no primeiro período,

Wojtyła recorre com profundidade à noção de experiência moral. A ética, explica, não surge de nenhuma estrutura externa ao sujeito, não é uma construção mental gerada por pressões sociológicas, nasce de um princípio real e originário: a experiência moral, a experiência do dever, porém não entendido de modo kantiano, como a estrutura formal da razão prática, senão em um sentido profundamente realista, como a experiência que todo sujeito possui - em cada ação ética concreta - de que deve fazer o bem e deve evitar o mal (tradução nossa).

\footnotetext{
${ }^{2}$ O Personalismo consiste num movimento filosófico nascido na França do século XX, fundado por Emmanuel Mounier (1905-1950), vinculado à revista "Esprit" que surgiu em 1932. O Personalismo, aliado aos ideais cristãos, afirma o valor intrínseco da pessoa humana, que está vinculado à dimensão comunitária; opondo-se tanto ao Capitalismo como ao Socialismo.
} 
Quanto ao ultimo, Juan Burgos aponta a eleição de Wojtyła para o encargo de Sumo pontífice da Igreja católica e a consequente interrupção de sua carreira acadêmica como justificativas para a ausência de grandes produções filosóficas que tratem das relações interpessoais e da filosofia social nos seus escritos. Com isso, Burgos expressa o não alheamento de Wojtyła das questões interpessoais e sociais, respaldado nos artigos de nosso filósofo, como “A pessoa: sujeito e comunidade" (1976).

Mesmo tendo encerrado sua produção estritamente filosófica, após ter assumido o encargo de papa, Wojtyła embasou os seus documentos pontifícios nos seus conceitos antropológicos e éticos de outrora.

Este artigo objeta, outrossim, enfatizar os temas da antropologia, enfatizando o corpo humano e as relações sociais, em Wojtyła.

\section{A dignidade pessoal e o corpo humano}

Segundo o pensamento antropológico de Wojtyła (2011, p. 295), em "Pessoa e ação", o corpo da pessoa humana é o "corpo próprio" do ser humano - de acordo com a fenomenologia; mais que um simples instrumento a serviço da alma, como entendera as filosofias antiga e moderna.

$\mathrm{Na}$ antropologia wojtyliana, o corpo é integrado na ação da pessoa pela liberdade de autodeterminação humana, mesmo com a reatividade corpórea e os impulsos, que são ligados ao corpo. Nesse sentido, a pessoa humana participa com a sua ação da construção do mundo e da sociedade ao se comportando com o pudor, como cuidado próprio do corpo, abrindo-se ao cuidado dos outros (alteridade), mediante a orientação presente na norma personalista. Segundo Wojtyła (1982, p.38):

Esta norma, no seu conteúdo negativo, afirma que a pessoa é um bem, o qual não está de acordo com a utilização, tendo em vista que não pode ser tratada como objeto de uso, portanto como um meio. Paralelamente aparece o conteúdo positivo da norma personalista: a pessoa é um bem tal que só o amor se relaciona com ela própria e plenamente.

O conceito wojtyliano de Norma personalista é formulado na obra Amor $e$ responsabilidade (1960). Nessa obra, Wojtyła polemiza contra a ética do Utilitarismo ${ }^{3}$ ao tratar

\footnotetext{
${ }^{3}$ A ética utilitarista que baseia "[...] na sua formulação definitiva, o princípio da utilidade (principium-utilitatis) exige o máximo de prazer e o mínimo de sofrimento para o maior número possível de homens” (WOJTYŁA, 1982, p.34). Nessa lógica utilitarista, cada pessoa humana deve estar como sujeito que instrumentaliza o outro, para obter o máximo de prazer, mas, simultaneamente, também é objeto a ser instrumentalizado pelos outros a fim de lhes
} 
da ética personalista a partir do amor entre homem e mulher, primando pela dignidade e interioridade da pessoa, dada pelo Ser divino.

Na concepção clássica do corpo humano, representada pelo paradigma platônico (cf: PLATÃO, 1981), o corpo é conceituado como "instrumento da alma", dado que o corpo é perecível e a alma é eterna. Então, a alma deve impor uma ética ao corpo a fim de que o ser humano seja justo e sua alma, pela felicidade alcançada na vivência das virtudes racionais, seja digna de uma feliz recompensa após a morte, quando a alma se liberta do "cárcere" corporal.

O corpo, no pensamento aristotélico (cf: ARISTÓTELES, 2010, p. 96-97), é tudo o que se estende no espaço e pode ser dividido em qualquer direção. Esta noção foi retomada por René Descartes (1999), que afirmara que o corpo é "substância extensa" distinta da alma, a “substância pensante". Da conceituação da extensão corporal, presente nos pensamentos clássico e moderno, a diferenciação existente é que para Descartes o corpo é uma substância distinta da alma, ao passo que para Platão (1981, p. 109), o corpo está submetido, dependendo da alma.

$\mathrm{Na}$ contemporaneidade, a partir das correntes filosóficas: Fenomenologia e Existencialismo, o pensador Gabriel Marcel (1887-1973) ${ }^{4}$ criticou as concepções de corpo como instrumento e objeto, e defendeu a concepção de corpo próprio, a partir da cinestesia que acontece na vivência humana em meio ao mundo mediante o corpo, ainda que seja finito na experiência de morrer (cf: MARCEL, 2005, p.299). Sobre isso, Abbagnano (2007, p.249) comentou que "Marcel criticou a ideia de corpo objeto e de corpo instrumento. O meu corpo não pode ser um objeto porque é constantemente percebido como próprio (cinestesia) por parte do sujeito. Será preciso dizer, então, que 'sou meu corpo' e que existir equivale a 'estar encarnado"” (itálico nosso).

Com esta orientação panorâmica, na história da filosofia, acerca da concepção de corpo humano, compreende-se o pensamento antropológico de Karol Wojtyła no que toca à dimensão somática da pessoa humana, como uma síntese das concepções: clássica e moderna (corpo instrumento) e contemporânea (corpo próprio), quando expõe a integração do corpo na ação pessoal.

conferir prazer. Nessa forma ética, o prazer é considerado sinônimo de felicidade, que é subjetiva. Wojtyła critica ferrenhamente o princípio utilitarista, sobremaneira quando aplicado nas relações amorosas entre homem e mulher. ${ }^{4}$ Filósofo francês vinculado ao chamado "Existencialismo cristão". Marcel fundamentou seu pensamento nas filosofias tomista, hegeliana e fenomenológica. Dentre suas obras se destacam: "Jornal metafísico" (1927), "Ser e ter" (1935) e "Homo viator"(1944). 


\section{Integração do corpo na ação}

Na obra "Pessoa e ação", Wojtyła evidencia a integração do corpo na ação da pessoa. A dinâmica do corpo é coordenada pelo princípio de reatividade peculiar ao corpo animado; este princípio da reação corporal é vinculado aos impulsos de autoconservação e de perpetuação da espécie, que no ser humano se liga à afirmação da existência. Conforme o pesquisador do pensamento wojtyliano, Paulo Silva (2005, p.83),

o dinamismo do homem, puramente somático, pode ser considerado reativo. A potencialidade que se encontra, em sua raiz, pode ser denominada reativa [...]. A ideia de reação se aplica a diversos elementos da conduta do homem e a diversas formas de atuar. Esse fato implica que o fator da reatividade do corpo se encontra profundamente na raiz de todo atuar da pessoa humana.

$\mathrm{Na}$ antropologia wojtyliana, a ação corporal deve ser orientada para se tornar "actus personae - ação da pessoa" (cf: WOJTYŁA, 2011, p.224). Assim, a ação do ser humano é tipicamente pessoal quando obedece à autodeterminação da pessoa dada na vontade consciente, através do querer que administra a ação da pessoa no mundo, orientando a reatividade somática. Deste modo, dá-se a integração do corpo humano na ação pessoal, como afirma Wojtyła (2011, p. 276): "No conceito de autopossessão está incluída a pessoa como alguém que se possui a si mesmo, ao mesmo tempo que é possuído por si [...] a ideia de autodomínio inclui a pessoa tanto como alguém que se governa a si mesmo e se subordina a si mesmo"(tradução nossa).

Wojtyła concebe a ideia de integração do corpo à ação pessoal, mediante a integração da reatividade, que é junção de corpo e ação, na personalidade humana, através da sujeição do corpo ao querer consciente da pessoa humana. Desse modo, para que se vivencie o corpo como próprio, na antropologia wojtyliana, a ação corporal deve ser coerente com as decisões pessoais, manifestando deste modo a transcendência da pessoa.

\section{Norma personalista e pudor}

Se há a integração da ação corporal na personalidade humana, mediante a autodeterminação, a pessoa humana está em condições favoráveis de se dar a norma personalista, visando ao bem de todas as pessoas, inclusive ao seu.

O corpo integrado na ação pessoal corresponde à exigência da dignidade da pessoa humana, ressaltada na ética do amor de Wojtyła. Neste rumo, o "corpo próprio" ou "corpo 
pessoal", assim como a pessoa toda, é objeto da norma personalista. Isto implica a exigência do pudor como zelo peculiar ao corpo pessoal, que revela a pessoa humana na sociedade. Para Wojtyła (1982, p.160),

o valor da pessoa está estritamente vinculado à sua inviolabilidade, por ser ela mais que um "objeto de uso". O pudor sexual, de certo modo, instintivamente defende esta colocação, portanto defende também o valor da pessoa. Mas não se trata apenas de defender. Trata-se de revelar, por assim dizer, este valor, e precisamente revelá-lo junto com os valores sexuais que estão ligados à pessoa.

O pudor sexual visa à preservação da dignidade pessoal do corpo humano para que a exposição dos membros corporais que despertam o desejo sexual seja restrita à convivência matrimonial, evitando que o corpo da pessoa seja considerado, assim como a pessoa, como meio a ser utilizado, ao invés do que realmente é: fim em si. ${ }^{5}$

Este cuidado para com o corpo, além de visar à própria dignidade pessoal, também impõe a preservação da dignidade das demais pessoas, seja no modo de se trajar, seja nas expressões artísticas. A aplicação da norma personalista vinculada ao pudor sexual visa sempre ao bem da alteridade, ao bem comum que segue pari passu ao bem pessoal.

\section{Participação e alienação}

Na convivência comunitária, embasada no bem comum, o ser humano vivencia a integração das ações corporais na sua personalidade, mediante a autodeterminação, possuindo a si mesmo no processo de "participação" nas relações interpessoais. Nesse horizonte, Wojtyła (2005, p.119) conceitua a "participação" como

atualização do esquema "eu mesmo - o outro" derivando de ser consciente do fato da humanidade em um determinado ser humano diferente de mim, um dos outros, porém sucede por ter experiência do outro "eu" como pessoa. A participação indica a personalização fundamental da relação de um ser humano com outro ser humano (tradução nossa).

A participação se dá nas relações interpessoais, acentuando o respeito entre as pessoas e a dignidade presente em cada pessoa humana que exige a prática da norma personalista. Nesta visão, participação é o oposto de "alienação". Com efeito, diz Wojtyła (2005, p.125):

\footnotetext{
${ }^{5} \mathrm{O}$ pensamento ético de Wojtyła, está de acordo com o do filósofo Immanuel Kant (1724-1804) formulado na obra "Fundamentação da metafísica dos costumes", o princípio de não instrumentalização do sujeito, referindo-se à pessoa humana sempre como fim de toda ação humana (cf: KANT, 1992).
} 
A alienação não é, [...] senão o contrário da participação, a debilitação ou inclusive a anulação da possibilidade de experimentar outro ser humano como "outro eu", é ele a causa de uma certa deformação do esquema "eu- outro" [...] com a palavra alienação se caracteriza uma situação ou condição de um ser humano que não se permite experimentar outro ser humano como "outro eu" (tradução nossa).

O processo de "alienação" acontece em não considerar o outro na sua humanidade e personalidade, o que impede uma autêntica relação interpessoal, impossibilitando a vivência da norma personalista e minando os alicerces das vidas familiar e comunitária.

Então, partindo dos princípios metafísicos e éticos da norma personalista, sempre visando ao bem da pessoa humana, a "participação" é sempre o processo adequado que oportuniza a vivência das relações interpessoais, constituindo, para Wojtyła, da família à sociedade.

\section{Abertura à alteridade}

No artigo intitulado "Pessoa: sujeito e comunidade" (1976), Wojtyła pensa as relações interpessoais e as relações comunitárias, conceituando a primeira por "Eu-tu" e a segunda por "Nós", como modo de levar em consideração as contribuições dadas à antropologia no realismo escolástico de Severino Boécio $(480-524)^{6}$, que conceitua o homem como "substância individual de natureza racional" no III capítulo da sua obra "Livro da pessoa e das duas naturezas contra Eutíquio e Nestório" (cf: BOETHIUS, 2006 , p.4), e as contribuições dadas pela gnosiologia moderna que concebe o ser humano como "sujeito". Destarte na relação "eutu”, para Wojtyła (2005, p.81): “O ‘tu' é outro 'eu’ distinto de mim. Pensando e dizendo 'tu', eu expresso ao mesmo tempo uma relação que de algum modo se projeta fora de mim, porém que ao mesmo tempo retorna também a mim" (tradução nossa).

Na relação "eu-tu", ocorre o encontro participativo entre dois sujeitos humanos, dando azo ao reconhecimento da dignidade pessoal presente em ambos. Alicerçada nesta relação, erige-se a relação denominada "nós", que origina a vitalidade comunitária e a sociedade, como a descreveu Wojtyła (2005, p. 90):

O "nós" indica, sobretudo, uma coletividade; esta coletividade, que podemos chamar sociedade, grupo social, etc., não possui em si um ser substancial, sem

${ }^{6}$ Filósofo medieval que fora cônsul do rei ostrogodo Teodorico. Estudou em Atenas, onde obteve um conhecimento enciclopédico. Sua principal obra, que trata da divina providência, é intitulada "Sobre a consolação pela filosofia". É considerado o primeiro-pensador-escolástico. 
embargo [...] o que deriva da acidentalidade, das relações entre os homenspessoas, apresenta-se em primeiro plano, fornecendo a base de um juízo, em primeiro lugar, sobre todos, e, em segundo lugar, sobre cada um nesta coletividade (tradução nossa).

Dessa maneira, a vivência da participação em todas as relações interpessoais (eu-tu) é o que fundamenta a participação social, seja no matrimônio, seja na comunidade. De fato, na relação "nós" há uma síntese entre as concepções escolástica e moderna acerca do ser humano, pois o ser humano não é mais visto unilateralmente como "substância individual de natureza racional", ou apenas como "sujeito", porém, é contemplado na sua integridade; não somente é conceituado deste modo, mas vivencia a sua personalidade, participando com os outros na construção do mundo. Assim, o seu corpo personalizado é integrado, mediante os gestos pessoais, na comunidade humana, visando a toda pessoa humana sempre como bem em si mesmo, conforme a prática do amor.

\section{Considerações finais}

$\mathrm{Na}$ ética do amor de Karol Wojtyła, o corpo humano encontra sua dignidade e corresponde ao que realmente é, ou seja, corpo pessoal. E o é à medida que exprime concretamente a ação da pessoa humana perante o outro, seja no matrimônio ou na comunidade. Afinal, para o filósofo polonês, a "lógica" da vocação da pessoa humana é fazer-se dom ao outro, na medida do amor.

Assim a pessoa humana exerce sua liberdade com relação ao seu corpo, não quando sofre a alienação deste, mas, quando participa com ele na construção do bem da alteridade. Nessa participação, a pessoa humana atua perante o outro, ou perante a comunidade, com os gestos corporais que expressam a livre decisão de sua consciência. É, pois, na consciência que reconhece segundo a verdade objetiva, que se pode tomar a decisão por fazer de si um dom ao outro através da vivência do amor, entregando-se pelos gestos corporais coerentes com a consciência pessoal.

Essa solução exige da pessoa a educação para o amor, de acordo com o princípio contido na norma personalista de Wojtyła. Esse princípio proporciona a abertura transcendente do ser humano à presença do Ser divino desde a interioridade de toda a pessoa humana, suscitando no ser humano o amor de doação pelo bem do outro, o que pode dar sólido fundamento às famílias e à sociedade. 


\section{REFERÊNCIAS BIBLIOGRÁFICAS}

ABBANGANO, Nicola. Dicionário de filosofia. 5.ed. São Paulo: Martins fontes, 2007.

ARISTÓTELES. Sobre a alma: tomo I. v.3..Lisboa: Imprensa Nacional-Casa da Moeda, 2010.

BERNSTEIN, Carl; POLITI, Marco. Sua santidade: João Paulo II e a História oculta de nosso tempo. Rio de Janeiro: Objetiva, 1996.

BOETHIUS, Severinus. Liber De Persona Et Duabus Naturis Contra Eutychen Et Nestorium. 2006. Disponível em: $<$ https://documentacatholicaomnia.eu/04z/z_04800524_Boethius._Severinus_Liber_De_Persona_Et_Duabus_Naturis_Contra_Eutychen_Et_ Nestorium_MLT.pdf.html>. Acesso em: 16 jul. 2020.

BURGOS, Juan Manuel. La filosofia personalista de Karol Wojtyła. Notes et documents, Madrid, n.6, p.5364, 2006. Disponível em: < https://pt.scribd.com/document/218603115/Lafilosofia-personalista-de-Karol-Wojtyla-JM-Burgos-pdf >. Acesso em 16 jul. 2020.

DESCARTES, René. Discurso do método; As paixões da alma; Meditações. São Paulo: Ed. Nova Cultural, 1999. (Os Pensadores).

KANT, Immanuel. Fundamentação da metafísica dos costumes. Lisboa: Edições 70, 1992.

MARCEL, Gabriel. Homo Viator: prolegómenos a uma metafisica de la esperanza. Salamanca: Sígueme, 2005.

PLATÃO. Fédon. In: Diálogos. São Paulo: Hemus ed., 1981, p. 99 - 178.

REALE, Giovanni; ANTISERI, Dario. História da filosofia: do romantismo até os nossos dias. São Paulo: Paulus, 1991, v. 3.

SILVA, Paulo Cesar da .A antropologia personalista de Karol Wojtyła: pessoa e dignidade no pensamento de João Paulo II. Aparecida: Idéias e letras, 2005.

WOJTYŁA, Karol. Amor e responsabilidade: estudo ético. São Paulo: Loyola, 1982. . El hombre y su destino: ensayos de antropología. 3. ed. Madrid : Palabra, 2005. Mi visión del hombre: hacia una nueva ética. 7. ed. Madrid: Palabra, 2010. .Persona y acción. Madrid: Palabra, 2011.

Artigo recebido em: 23/04/2020

Artigo aprovado em: 16/07/2020 